\title{
APPLICATION OF 2N DESIGN OF EXPERIMENT METHOD FOR THE EVALUATION OF THE EFFICIENCY AND CROSS-EFFECTS OF OILFIELD CHEMICALS
}

\author{
ZOLTÁN LUKÁCS ${ }^{* 1}$ AND TAMÁS KRISTÓF ${ }^{1}$ \\ ${ }^{1}$ Department of Physical Chemistry, Institute of Chemistry, University of Pannonia, Egyetem u. 10, \\ Veszprém, H-8201, HUNGARY
}

\begin{abstract}
It has been known for a long time that oilfield chemicals used for different purposes (corrosion and scale inhibitors, scavengers, biocides, etc.) can modify the efficiency of each other. These cross-effects can exhibit adverse or beneficial impacts and may modify the overall corrosiveness of the medium to a great extent. However, there is no standard procedure in order to evaluate the cross-effects, i.e. the extent to which the effect of one of the chemicals is modified by the addition of another. The $2 \mathrm{~N}$ Design of Experiment (DoE) method provides a robust and simple statistical way to evaluate the change in efficiency of oilfield chemicals owing to the addition of other additives. The $2 \mathrm{~N}$ DoE method can also be applied to other systems. In the present work the effects and cross-effects in systems consisting of a corrosion inhibitor, as well as an oxygen and a hydrogen sulphide scavenger are investigated and successfully demonstrated in a typical oilfield corrosion system with electrochemical corrosion monitoring methods.
\end{abstract}

Keywords: oilfield chemicals, corrosion inhibitor, Design of Experiment

\section{Introduction}

The chemical treatment of wet oils that are produced is a widely used method for mitigating unfavorable phenomena in the production, transportation and processing of crude oils: corrosion, scaling, emulsion forming, etc. On the way from the oil well to the refinery a variety of oilfield treatment chemicals are added to the oil: corrosion and scale inhibitors, biocides, hydrogen sulfide and oxygen scavengers (typically with wash waters), demulsifiers, anti-foam agents, etc. [1-4]. The effects of these chemicals are typically well defined in themselves, but the cross-effects, i.e. the influence on each other, are rarely discussed and even more rarely investigated, especially in situ. The reason for this is rather complex. From a practical perspective, there is no standard or wellestablished procedure for such testing. From a theoretical standpoint, the evaluation of such tests, if any, is rather problematic because if the effects of factors are strongly correlated (i.e. one or more "cross-effects" are significant in the system) then the evaluation of the effects by usual means (i.e. least square model fitting [5-7]) is subject to a significant error, if not impossible.

In order to formulate the problem, let us consider a dependent variable, $y$, e.g. the corrosion rate, and assume that it is a quantitative function of some other quantitative

\footnotetext{
*Correspondence: lukacs600131@gmail.com
}

independent variables:

$$
y=p_{1} x_{1}+p_{2} x_{2}+\cdots+p_{n} x_{n} .
$$

This is an uncorrelated multilinear model, that is, the $\left(p_{1}, \cdots, p_{n}\right)$ parameter set, the set of the factor coefficients, is invariant throughout the whole $\left(x_{1}, \cdot, x_{n}\right)$ model variable space. If the $\left(p_{1}, \ldots, p_{n}\right)$ parameter set is dependent on the location in the model variable space then the following correlated multilinear model can be applied:

$$
\begin{aligned}
& y=\quad p_{1} x_{1}+p_{2} x_{2}+\cdots+p_{n} x_{n}+ \\
& +q_{1,2} x_{1} x_{2}+\cdots+q_{n-1, n} x_{n-1} x_{n},
\end{aligned}
$$

where the $q_{1,2}, \cdots q_{n-1, n}$ coefficients represent the cross-effects coefficients (the effect of quadratic and higher order contributions is not discussed here). If the cross-effects are significant in a model, i.e. the coefficients of the cross-effects are comparable to the coefficients of the factors, then severe computational difficulties may occur, especially if a remarkable error (random or systematic) is superimposed on the measurement data. In such cases conventional parameter-fitting procedures generally fail to provide realistic and accurate model coefficients.

For the investigation of cross-effects, a viable technique is the so-called 2N Design of Experiment (DoE) method. As this method is not widely used in the field of corrosion science and technology, its basic concepts are outlined in brief here. 
In the methodology of the Design of Experiment technique the independent variables are known as factors and the values of the factors are referred to as factor levels. The factor levels are fixed, discrete values (in contrast to the continuous range of the independent variables). The variance in the factor levels, if any, will be transformed into a variance of the dependent variable. The Design of Experiment methods are typically used in industrial quality assurance testing, where the fixed factor levels correspond to certain standardized levels of the factors that are assumed to influence a quality parameter (i.e. the dependent variable). In oilfield chemical performance tests a fixed value with regard to the factor of the "corrosion inhibitor" can be the concentration recommended by the supplier. Apart from the fixing of the factor levels, the general Design of Experiment schemes and the supporting mathematical apparatus basically do not differ from conventional multilinear parameter fitting. However, a special type of DoE, the $2 \mathrm{~N}$ Design of Experiment method, possesses some noteworthy mathematical properties that make it especially applicable for studying cross-effects.

In the $2 \mathrm{~N}$ DoE method every factor possesses exactly two factor levels and they are normalized to -1 and +1 . In some cases, if all the factors are quantitative, a factor level of 0 exists in order to test the linearity of the model. With the normalization of the factor levels to -1 and +1 , all the factors and cross-effects are orthogonal, i.e. independently calculable from each other. This is a great advantage, making the method applicable to study cross-effects.

On the other hand, the normalization of the factor levels to the arbitrary -1 and +1 levels is costly. The coefficients of the factors and cross-effects, determined after the calculations, do not have any direct physical meaning, they can only be interpreted in terms of a comparison with one another and to the variance of the measurement data. A comparison of the factors and cross-effects with one another can yield a series of more and less significant effects and a comparison to the variance can provide information on the statistical significance of the respective factor/cross-effect. Obviously, the value of the obtained factor and cross-effect coefficients is dependent on the chosen spread between the two factor levels, therefore, this choice must be made with careful consideration. For example, if effects and interactions of oilfield chemicals are investigated, then one of the factor levels would be proposed to be "no chemical added" (concentration $=0$ ) and the other factor level would be termed as the chemical added to the fluid within the recommended range.

The purpose of this work was to demonstrate the applicability of the $2 \mathrm{~N}$ DoE method for studying the factors and cross-effects of oilfield chemicals in a suitably chosen model system.

\section{Experimental}

The model system was chosen as a typical corrosion system, containing a carbon steel electrode in a wellbuffered, slightly acidic electrolyte $\left(0.1 \mathrm{M} \mathrm{NaHSO}_{4}+\right.$ $0.1 \mathrm{M} \mathrm{Na}_{2} \mathrm{SO}_{4}$ ), which maintains a nearly constant corrosiveness and reduces the accumulation of solid corrosion products on the surface of the electrode which also improves the reproducibility of the tests. As the aim was to simulate the effects and cross-effects of oilfield chemical treatment additives (corrosion inhibitor, as well as hydrogen sulfide and oxygen scavengers), $1 \mathrm{mM}$ of $\mathrm{Na}_{2} \mathrm{~S}$ was added to the solution.

The carbon steel plates (three specimens) were applied for three parallel runs in each measurement set. The specimens were abraded with emery paper and then degreased in acetone for one hour. Before each run the species were etched in $5 \% \mathrm{HCl}$, degreased in an alkaline degreasing solution and etched in $5 \% \mathrm{HCl}$ again (all dippings lasted for a duration of 5 minutes). $600 \mathrm{~cm}^{3}$ of the solution was poured into a cylindrical test cell of $1000 \mathrm{~cm}^{3}$ in volume and a carbon steel plate electrode with a surface area of $17 \mathrm{~cm}^{2}$ was introduced into the cell, equipped with a silver/silver chloride $(3.5 \mathrm{M})$ reference electrode and two mixed metal oxide-coated titanium tube counter electrodes both $3 \mathrm{~mm}$ in diameter and $50 \mathrm{~mm}$ in length. The solution was not de-aerated and the measurements were conducted at room temperature (25 $\left.{ }^{\circ} \mathrm{C}\right)$.

The corrosion rate was determined by impedance measurements carried out at $1 \mathrm{kHz}$ and $0.1 \mathrm{~Hz}$ with a 20 $\mathrm{mV}$ p-p amplitude AC signal superimposed on the corrosion potential, which was established to a satisfactorily stationary level (max. $1 \mathrm{mV} / \mathrm{min}$ drift) of no more than 10 minutes. The polarization resistance of the electrode was determined by subtracting the high-frequency resistance (solution resistance) from the low-frequency resistance. The measurements were conducted by an Electroflex EF430 potentiostat and a PicoScope 3403D oscilloscope. The results were cross-checked by a Metrohm potentiostat. In order to simulate the components of a typical oilfield chemical treatment procedure, a commercial corrosion inhibitor (BPR 81100, Baker Hughes, 100 ppm), zinc acetate as a model compound for a hydrogen sulfide scavenger at a concentration of $2 \mathrm{mM}$, and sodium metabisulfite $\left(\mathrm{Na}_{2} \mathrm{~S}_{2} \mathrm{O}_{5}\right)$ also at a concentration of $2 \mathrm{mM}$ were added. All chemicals were of p.a. quality. The $2 \mathrm{~N}$ DoE scheme is shown in Table 1 below. All experimental sets were repeated 3 times with different electrodes.

\section{Results and Discussion}

The effect of three factors (a corrosion inhibitor, as well as hydrogen sulfide and oxygen scavengers) was studied on the polarization resistance (compensated for by the ohmic drop in the solution, see the previous Section) and the corrosion current. The relationship between the po- 
Table 1: Levels of factors and cross-effects of factors in the DoE sets.

\begin{tabular}{c|ccc|ccc}
\hline Set \# & \multicolumn{3}{|c|}{ Factors } & \multicolumn{3}{c}{ Factor cross effects } \\
Corrosion & $\begin{array}{c}\text { Hydrogen } \\
\text { inhibitor }\end{array}$ & $\begin{array}{c}\text { Oxygen } \\
\text { sulfide scavenger } \\
\text { scavenger }\end{array}$ & $\begin{array}{c}\text { Corrosion inhibitor } \times \\
\text { Hydrogen sulfide } \\
\text { scavenger }\end{array}$ & $\begin{array}{c}\text { Corrosion inhibitor } \times \\
\text { Oxygen scavenger }\end{array}$ & $\begin{array}{c}\text { Hydrogen sulfide } \\
\text { scavenger } \times \\
\text { Oxygen scavenger }\end{array}$ \\
\hline 1 & -1 & -1 & -1 & 1 & 1 & 1 \\
2 & -1 & -1 & 1 & -1 & -1 & -1 \\
3 & -1 & 1 & 1 & -1 & -1 & -1 \\
4 & -1 & 1 & -1 & -1 & -1 & 1 \\
5 & 1 & -1 & -1 & 1 & 1 & -1 \\
6 & 1 & -1 & 1 & 1 & -1 \\
7 & 1 & 1 & 1 & 1 & 1 \\
8 & 1 & 1 & & & 1 \\
\hline
\end{tabular}

larization resistance and the corrosion current was calculated as:

$j_{0}[A]=\frac{1}{2.303} \frac{\left(b_{a}^{-1}[V]+b_{c}^{-1}[V]\right)^{-1}}{R_{p}[\Omega]}=\frac{1}{2.303} \frac{0.04[V]}{R_{p}[\Omega]}$,

with a typical value of $b_{a}=0.06 \mathrm{~V} /$ decade and $b_{c}=0.12$ V/decade, furthermore, $R_{p}$ is measured in Ohms and $j_{0}$ in Amperes. The units of measurement are shown in square brackets.

The Design of Experiment scheme is shown in Table 1 The scheme consists of $2^{3}=8$ sets. The levels of interactions (cross-effects) are simply the product of the levels of the respective factors.

The original assumption of the work was that the polarization resistance and/or the corrosion current of the test specimen depend on the factors according to the following model:

$$
Y_{S}=\bar{Y}+\sum_{f} A_{f} E_{f}+\sum_{i} B_{i} E_{i}
$$

where $Y_{S}$ stands for the value of the target function in the respective set (the polarization resistance or corrosion current), $\bar{Y}$ denotes the total average of the same, $E_{f}$

Table 2: Factors (in diagonal cells), cross-effect coefficients and the variance of the measurement data for the evaluation of polarization resistance values. Values larger than the standard deviation are set in bold.

\begin{tabular}{c|c|c|c}
\hline Factors & $\begin{array}{c}\text { Corrosion } \\
\text { inhibitor }\end{array}$ & $\begin{array}{c}\text { Hydrogen } \\
\text { sulfide scavenger }\end{array}$ & $\begin{array}{c}\text { Oxygen } \\
\text { scavenger }\end{array}$ \\
\hline $\begin{array}{c}\text { Corrosion } \\
\text { inhibitor }\end{array}$ & $\mathbf{3 . 3 5 9}$ & -1.086 & $\mathbf{- 3 . 3 1 9}$ \\
\hline $\begin{array}{c}\text { Hydrogen } \\
\text { sulfide scavenger }\end{array}$ & & 0.022 & -0.082 \\
\hline $\begin{array}{c}\text { Oxygen } \\
\text { scavenger }\end{array}$ & & $-\mathbf{3 . 0 8 7}$ \\
\hline $\begin{array}{c}\text { Standard } \\
\text { deviation of } \\
\text { measurement } \\
\text { data }\end{array}$ & \multicolumn{3}{|}{} \\
\hline
\end{tabular}

and $E_{i}$ represent the level of the respective factor/crosseffect in the respective set $(-1$ or +1$)$, and $A_{f}$ and $B_{i}$ are the values of the respective effect/interaction coefficients. The overall standard deviation of the measurement data was determined via

$$
\sigma(Y)=\sqrt{\frac{1}{S(J-1)} \sum_{s=1}^{S} \sum_{j=1}^{J}\left(Y_{s, j}-\bar{Y}_{s}\right)^{2}}
$$

where $S=8$ is the number of sets, $J=3$ stands for the number of runs per set, $Y_{s, j}$ denotes the measurement result (polarization resistance or the corrosion current) and $\bar{Y}_{s}$ represents the average of the latter for a certain set.

The results based on the model of Eq. 4 are included in Tables 2 and 3 for the polarization resistance and corrosion current, respectively.

By comparing the coefficients in the tables above it is striking at first sight that - apart from the coefficient of the corrosion inhibitor factor, which possesses the greatest absolute value in both tables - there is great variation in the relative significance of the corresponding values. It could be expected that if a factor/cross-effect is more significant in the model describing the variations of the

Table 3: Factors (in diagonal cells), cross-effect coefficients and the variance of the measurement data for the evaluation of corrosion current values. Values larger than the standard deviation are set in bold.

\begin{tabular}{c|c|c|c}
\hline Factors & $\begin{array}{c}\text { Corrosion } \\
\text { inhibitor }\end{array}$ & $\begin{array}{c}\text { Hydrogen } \\
\text { sulfide } \\
\text { scavenger }\end{array}$ & $\begin{array}{c}\text { Oxygen } \\
\text { scavenger }\end{array}$ \\
\hline $\begin{array}{c}\text { Corrosion } \\
\text { inhibitor }\end{array}$ & $\mathbf{- 9 . 0 6 \cdot \mathbf { 1 0 } ^ { - \mathbf { 4 } }}$ & $\mathbf{7 . 3 9} \cdot \mathbf{1 0}^{-\mathbf{4}}$ & $\mathbf{8 . 7 1} \cdot \mathbf{1 0}^{-\mathbf{4}}$ \\
\hline $\begin{array}{c}\text { Hydrogen } \\
\text { sulfide } \\
\text { scavenger }\end{array}$ & $\mathbf{- 7 . 3 1 \cdot \mathbf { 1 0 } ^ { - \mathbf { 4 } }}$ & $\mathbf{7 . 4 5} \cdot \mathbf{1 0}^{-\mathbf{4}}$ \\
\hline $\begin{array}{c}\text { Oxygen } \\
\text { scavenger }\end{array}$ & & $-3.98 \times 10^{-4}$ \\
\hline $\begin{array}{c}\text { Standard } \\
\text { deviation of } \\
\text { measurement } \\
\text { data }\end{array}$ & $\mathbf{4 . 5 5} \cdot \mathbf{1 0}^{-\mathbf{4}}$ & \\
\hline
\end{tabular}


Table 4: Factors (in diagonal cells), cross-effect coefficients and the variance of the measurement data for the evaluation of the logarithm of the polarization resistance values. Values larger than the standard deviation are set in bold.

\begin{tabular}{c|c|c|c}
\hline Factors & $\begin{array}{c}\text { Corrosion } \\
\text { inhibitor }\end{array}$ & $\begin{array}{c}\text { Hydrogen } \\
\text { sulfide } \\
\text { scavenger }\end{array}$ & $\begin{array}{c}\text { Oxygen } \\
\text { scavenger }\end{array}$ \\
\hline $\begin{array}{c}\text { Corrosion } \\
\text { inhibitor }\end{array}$ & $\mathbf{0 . 2 7 5}$ & -0.143 & $-\mathbf{0 . 2 6 6}$ \\
\hline $\begin{array}{c}\text { Hydrogen } \\
\text { sulfide } \\
\text { scavenger }\end{array}$ & & 0.110 & -0.117 \\
\hline $\begin{array}{c}\text { Oxygen } \\
\text { scavenger }\end{array}$ & & -0.110 \\
\hline $\begin{array}{c}\text { Standard } \\
\text { deviation of } \\
\text { measurement } \\
\text { data }\end{array}$ & & $\mathbf{0 . 1 7 2}$ & \\
\hline
\end{tabular}

polarization resistance, then the same factor/cross-effect will exhibit approximately the same relative significance in the model of the corrosion current. However, in this case great differences exist in terms of the relative significance. The coefficient of the factor concerning the hydrogen sulfide scavenger and its cross-effect with the oxygen scavenger are both negligible in the model of the polarization resistance ( Table 2) and much more significant (compared to the standard deviation of the measurement data in Table 3). This magnitude of the differences cannot simply be attributed to some changes with regard to the weighing of measurement data due to the reciprocal transformation from the polarization resistance to the corrosion current (cf. Eq. 3 and raises doubts suggesting that the model in Eq. 4 is invalid. Eq. 4 suggests that the contribution of the additives (corrosion inhibitor and the scavengers) to the dependent variable is a linear function of the concentration. However, if it is taken into consideration that the effects of the additives are basically kinetic, then it can be implied that instead of the linear Eq. 4 a logarithmic approximation might exist:

$$
\ln Y_{S}=\ln \bar{Y}+\sum_{f} A_{f} \ln E_{f}+\sum_{i} B_{i} \ln E_{i}
$$

which is in agreement with the general experience that the effects (activities) of components are proportional to the logarithm of concentration. By applying Eq. 6, the factors and cross-effect coefficients of the models for the polarization resistance and corrosion current will be identical apart from a multiplicator of $(-1)$.

The model-fitting results of Eq. 6 are shown in Table 4 for the polarization resistance data. From the results it can be concluded that the corrosion inhibitor has the greatest effect on the system and it increases the polarization resistance significantly. The hydrogen sulfide scavenger also decreases the corrosion rate in itself, but its application along with the corrosion inhibitor is less favorable. The use of an oxygen scavenger is not at all advisable under these conditions.

\section{Summary}

The general aspects of the $2 \mathrm{~N}$ Design of Experiment method and also a specific application for a chemical treatment model system were discussed. The effects and interactions of a corrosion inhibitor, as well as hydrogen sulfide and oxygen scavenger model compounds were studied. The linear model for these additives yielded controversial results, namely the fitting of the model on the polarization resistance data provided totally different results to those on the corrosion current data. By applying the logarithmic model, the results are consistent and their interpretation straightforward.

It has been proven that - by carefully selecting the appropriate mathematical model - the proposed method is applicable for the investigation of the effects and crosseffects of different oilfield treatment chemicals.

\section{Acknowledgement}

Present article was published in the frame of the project GINOP-2.3.2-15-2016-00053 ("Development of engine fuels with high hydrogen content in their molecular structures (contribution to sustainable mobility)").

\section{REFERENCES}

[1] Rahmani, Kh.; Jadidian, R.; Haghtalabb, S.: Evaluation of inhibitors and biocides on the corrosion, scaling and biofouling control of carbon steel and copper-nickel alloys in a power plant cooling water system, Desalination, 2016 393(1), 174-185 DOI: 10.1016/j.desal.2015.07.026

[2] Barmatov, E.; Hughes, T.; Nagl, M.: Efficiency of film-forming corrosion inhibitors in strong hydrochloric acid under laminar and turbulent flow conditions, Corr. Sci., 2015 92, 85-94 DOI: 10.1016/j.corsci.2014.11.038

[3] Papavinasam, S.: Corrosion Control in the Oil and Gas Industry, Chapter 7 - Mitigation - Internal Corrosion (Elsevier, Amsterdam) 2014 p. 361 ISBN: 978-0-12-397022-0

[4] Song, G.-L.: The grand challenges in electrochemical corrosion research, Front. Mater., 2014 1(2), 1-3 DOI: 10.3389/fmats.2014.00002

[5] Giunta, A.A.; Wojtkiewicz Jr., S.F.; Eldred, M.S.: Overview of modern design of experiments methods for computational simulations, Proceedings of 41st Aerospace Sciences Meeting and Exhibit 2003; Reno, NV; USA. AIAA 2003-0649 
[6] Garud, S.S.; Karimi, I.A.; Kraft, M.: Design of computer experiments: A review, Comput. Chem. Eng., 2017 106, 71-95 DOI: 10.1016/j.compchemeng. 2017.05.010
[7] Kemény, S.; Deák, A.: Kísérletek tervezése és kiértékelése [Design and Evaluation of Experiments, in Hungarian] (Múszaki Könyvkiadó, Budapest) 2002 ISBN: 978-963-2799-12 